\title{
17. Agroclimatic Modeling as a Research Tool in Brazil
}

\author{
Fernando L. Garagorry \\ and Everaldo R. Porto
}

\section{INTKODUCTION}

This paper illustrates the use of an agroclimatic model to suggest agricultural research priorities in Brazil. More generally, several aspects of the modeling activities conducted at EMBRAPA (the Brazilian Public Corporation for Agricultural Research) will be discussed. The goal of modeling and simulation at EMBRAPA is to obtain several feedbacks that act upon researchers and research managers, helping them to gain understanding about complex systems and to set reasonable research priorities.

\section{THE USE OF THE SYSTEMS APPROACH AT EMBRAPA}

Modeling at EMBRAPA is done within the general framework of the systems approach applied to agricultural research (Alves 1975; Dent and Anderson 1971; Dalton 1975; Spedding 1979).

Figure 17.1 lists some of the systems of interest to EMBRAPA. The labels attached to these systems are not very descriptive; for instance, "PESTS" may refer to an insect/plant/water system whose description requires a lengthy paper. The important point is that EMBRAPA takes farms as the focal systems to be studied. All other systems, which may range from the whole country to a single animal, should be studied relative to the recommendations that must be given to farmers. For example, the study of an agroclimatic system of the weather/soil/plant type for the semiarid region of Brazil is considered essential to the development of technologies that are acceptable to farmers.

Several activities must be carried out if the systems approach is to be used. On one side, we have traditional activities, which can be grouped roughly into experimentation and sampling. They are essentially analytical, and have dominated agricultural research up to the present day. On the other side, new activities should be developed parallel to the ones that have characterized the experiment station. These include the use of mathematical (computer) modeling, the execution of case studies, and the development of large information systems (e.g., a climatic data base).

These new activities are essentially synthetic, at least in the sense that they simultaneously take into account a large number of interrelated variables. In addition, in connection with computer 


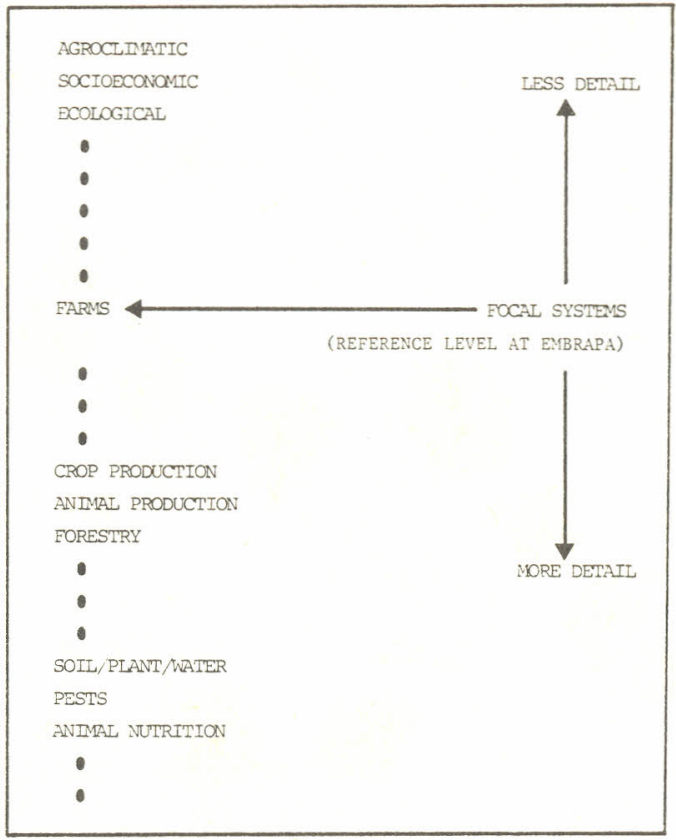

FIGURE 17.1 Examples of systems to be considered.

models and case studies, an effort is made to study not only how but also why the system works the way it does. This central aspect of the systems approach requires synthesis rather than analysis (Ackoff $1979 a, 1979 b)$. In this context, synthesis means not only the combination of the different components of a system, but also the consideration of larger systems. For instance, to study farming systems in the semiarid tropics of Brazil, it was necessary to study an agroclimatic system at the county level. The study of other systems related to economics, marketing, and employment was also required. For example, if an agroclimatic or a farm management model indicates that the best thing to do is to plant melons, and most farmers in a region follow this recommendation, the result may be an economic disaster because of market saturation resulting in a price drop.

THE ROLES OF MODELING AND SIMULATION

In this section, we will discuss the main functions associated with modeling and simulation activities at EMBRAPA. At this stage, it is assumed that a group of researchers has identified an important system, and that they are willing to allocate a substantial part of their time to its study.

We can take as an example a water/soil/plant system that can be common to many farmers in a region. Typically, the researchers have some knowledge and biological data relevant to the study. Data are obtained through the use of traditional techniques applied within the work of specific disciplines (plant physiology, soil physics, water management, etc.). We are not referring here to climatic data that have been recorded over the years; comments on the availability of climatic data will be made later.

Suppose it is found that a mathematical model can be useful in understanding how and why a system works and how it can be changed or controlled. The model is not an end in itself, but a means to gain understanding. As soon as we begir building the model, probably with the help of a modeling expert, the first feedback acting upon the researchers clearly appears (indicated by [1] in figure 17.2). It is discovered very soon that the available knowledge and data are not enough to build the model. Researchers must perform several activities, such as reviewing the literature, formulating new hypotheses, and holding discussions with other scientists. The original multidisciplinary team then starts to work in an interdisciplinary way by combining the points of view and the techniques of several disciplines (Birnbaum 1979; Payne and Pearson 1979).

Then, using available information, a mathematical model is formulated. At this stage, a second feedback (indicated by [2] in figure 17.2) can be activated through the use of simulation, which in this context means numerical experimentation, including parameterization and sensitivity studies. Simulation can indicate points at which more research is necessary, together with others at which the available knowledge should be considered satisfactory. Simulation can also point to several weaknesses in the model, allowing corrections to be made.

These two feedbacks are the nost important at the present stage of modeling activities at EMBRAPA. Depending upon the system under study and the available model, other feedbacks can be activated. For instance, we can show the model outputs to external experts, extension agents, or farmers, and ask them to criticize the results. In general, however, our current models are not intended to advise farmers directly; they are considered to be research tools.

OUTLINE OF AN AGROCLIMATIC MODEL

In this section, we will present an overview of an agroclimatic model for the semiarid tropics of Brazil. A summary of the model's main aspects appears in figure 17.3 .

The system is of the water/soil/plant type. For each planting period and for each year, water balance is calculated and productivity is estimated. A list of the system's components follows.

1. Geographic boundary: A county with a meteorological station. 2. Crops: Only annual crops are considered.

3. Climatic data: The model requires daily rainfall data for a series of years--typically, between 20 and 50 years are available--and mean monthly temperature and relative humidity. In the present version, solar radiation and potential evapotranspiration are calculated with formulas proposed by Hargreaves that make use of temperature and relative humidity data and take into account the latitude of the meteorological station. The compute program, written with small modules, is very flexible, so that 


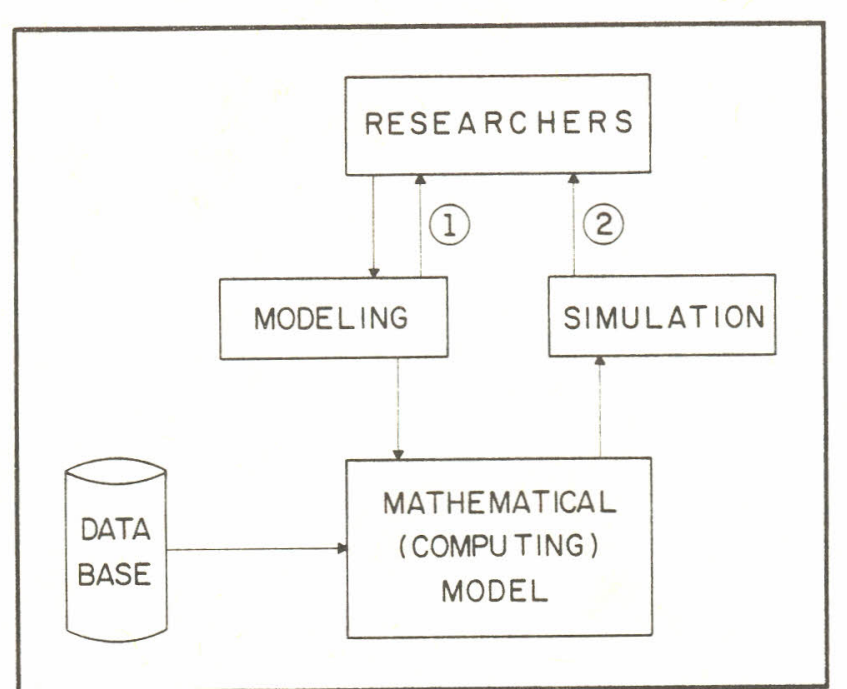

FIGURE 17.2 Two main feedbacks produced by modeling and simulation.

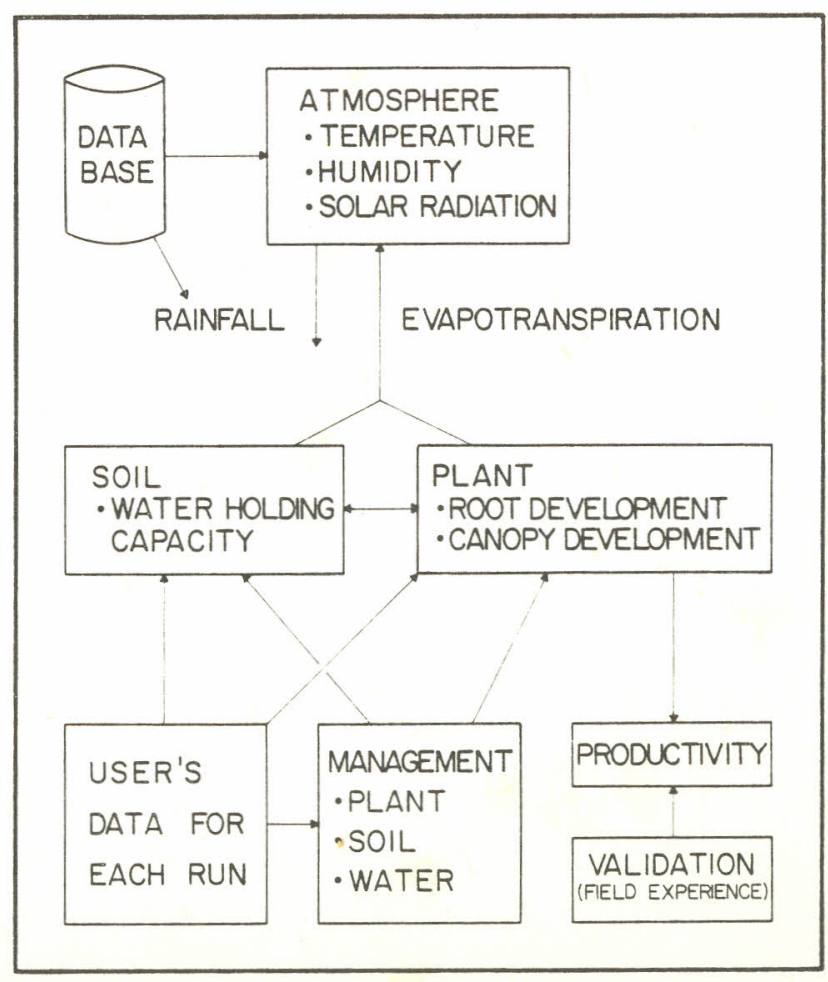

FIGURE 17.3 Basic components of an agroclimatic model for the semiarid tropics of Brazil (annual crops). different routines can be used to estimate potential evapotranspiration.

4. Soil: Water-holding capacity is estimated for the most prevalent type of agricultural soil in the county.

5. Plant: Root development is estimated for the crops of interest (mainly corn, beans, and sorghum) and for the chosen type of

soil. Evapotranspiration coefficients are estimated or are taken from the literature.

6. Simulation step: The user specifies the length of the planting period (typically five days). If one chooses five days, the year is divided into 73 periods. Then, the daily rainfall and potential evapotranspiration values are grouped into five-day values.

7. Productivity: For each planting period and each year, the model estimates productivity (defined as the ratio between actual and potential production) as a function of water stress. Different response functions can $b \in$ easily tested. The user must give two values between 0.0 and 1.0 , so to 1 s ductivity into "good," "fair," or "bad." For instance, if PROD is the estimated productivity and the values 0.8 and 0.5 are is the estimated productivity and the values 0.8 and 0.5 are
given, then the result is considered to be good if PROD $\geq 0.8$, fair if $0.8>$ PROD $\geq 0.5$, and bad if $\mathrm{PKOD}<0.5$.

8. Outputs: The computer gives two kinds of outputs: numerical and graphic. For each planting period, the program gives the reiative frequency of good, fair, and bad productivity results. (The relative frequency of "acceptabie" results, defined as the sum of good and fair ones, is also printed.) In addition, mear runoff and mean water deficit are printed, and all values are displayeć graphically.

9. Validation: The model results corresponcing to each of the past 10 years with available weather data are compared to field experience, with the cooperation of farmers and extension agents.

USE OF THE MODEL

\section{Example 1}

We consider the county of Irecê, the main bean-producing county in Brazil, in the state of Bahia. Beans are the chosen crop.

We will illustrate the use of the model with a simulation that takes the form of a traditicnal $2 \times 2$ factorial experiment. Most people would say that we are running four simulations. We prefer to say that we run one simulation that consists of four trials, so that the term simulation corresponds to a hypothetical field experiment, and each trial is equivalent to one experimental plot.

In order to run the model, the user must give a set of evapotranspiration coefficients $(k)$ and a set of yield response factors $(k)$. There are two sources for these sets of values: they can be taken from the literature, or they can be estimated by our researchers. Thus, we have four combinations that take the form of a $2 \times 2$ factorial experiment.

Here, for convenience, we will indicate by "FAO" (Food and Agriculture Organization of the United Nations) the values given by Doorenbos and Kassam (1979), and by "EMBRAPA" the values estimated by their researchers at the Center for Agricultural Research of the 
Semiarid Tropics (CPATSA). Table 17.1 sumarizes some of the results printed by the computer.

Conclusions. Several conclusions can be deduced from the study of the computer output. We list here a few of them.

1. The best planting season is in late October and early November, in agreement. with field experience.

2. A 35 percent chance of years with acceptable yieid (one out of three years) is much closer to field experience than the 62 percent value.

3. The model is very robust with regard to $k_{c}$ values, for either set of $k$ values

4. The model is very sensitive with regard to $k_{y}$ values, for either set of $k_{c}$ values.

Recommendations. Several recommendations can be submitted to the researchers so they can set more reasonable priorities. Of course, the ultimate decision may depend on several factors not included in the model or completely independent of the system urder includy (e.g., the availability of personnel or equipment). We list stud the rearchers that are valid for Irecê.

1. Do not plan any "best planting period" field experiment, since the model already gives reasonable and robust results.

2. Give high priority to the study of different water stress

response functions. Plan some experiment where the plots are

submitted to different levels of water stress at different stages

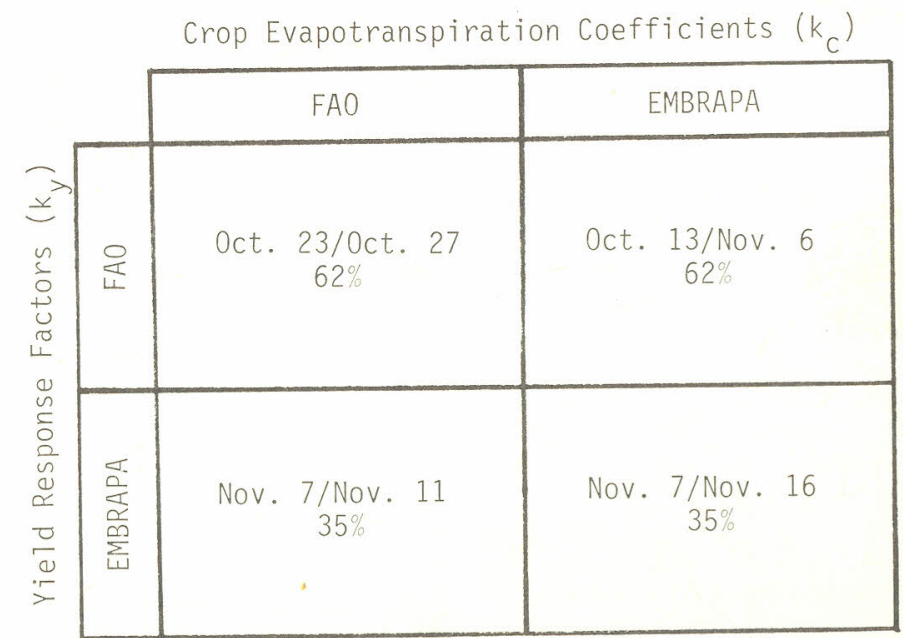

TABLE 17.1 Best planting interval and percentage of years with acceptable yield (county: Irecê, crop: beans). of the plant growth cycle. In other simulations use the $k$ values estimated at CPATSA, since the results they give are close to field experience.

3. Give low priority to any new estimation of the $k$ values; the values in the iiterature should be considered satisfactory for the present.

Example 2

The county of Santana do Ipanema, in the state of Alagoas, is also in the semiarid tropics of Brazil, but differs quite clearly from Irecê with regard to dominant soils and rainfall distribution. A simulation analogous to the one in the previous example was perA simuiation analogous to the one in the previous example was performed for Santana ao Ipanema, where 57 years of rainfall data were available. Models for the Ipanema region also differ from those designed for Irecê with respect to root development data; the Ipanema nodel recuires this information in order to relate soil type to plant growth. iable 17.2 gives a summary of the results for this example.

From the examination of the computer output we conclude that the results are very robust with regara to different sets of $k$ and $k$ values. Therefore, for the time being, we do not see any urgency to repeat the field experiments in order to improve our estimates of the $k$ and $k$ coefficients. In other words, the model suggests that this ${ }^{c}$ ort of ${ }^{y}$ field experiment has low priority in that county.

Crop Evapotranspiration Coefficients $\left(k_{c}\right)$

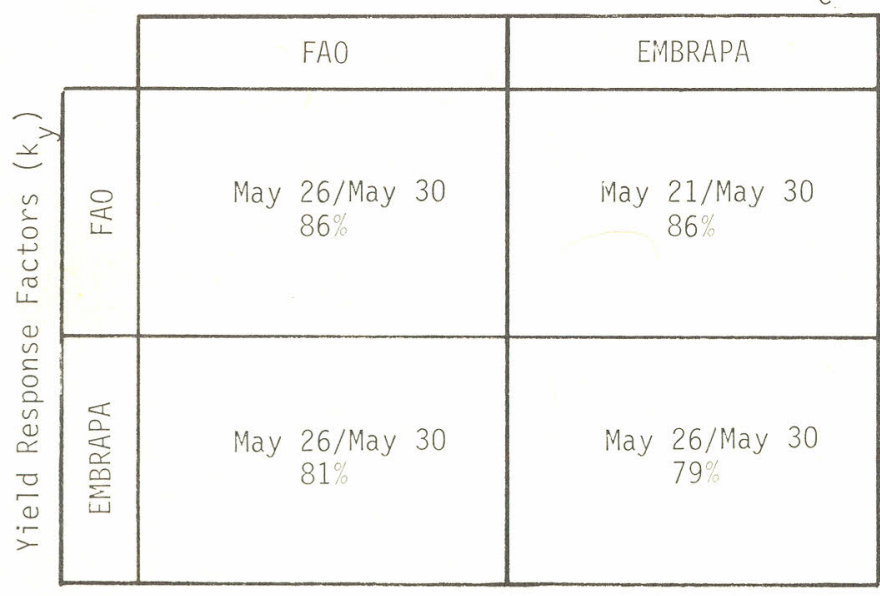

TABLE 17.2 Best planting interval and percentage of years with acceptable yield (county: Santana do Ipanema, crop: beans). 


\section{Example 3}

The irrigation specialists at CPATSA have developed or adapted some water management technologies that can be of great help for small farmers. These technologies are based on the storage of runoff water that can be used in drought periods. Some technologies that can enhance yields already exist, if the farmers could store at least $100 \mathrm{~mm}$ of runoff water. The model shows that in all the counties already studied, there are several periods with runoff well above the $100 \mathrm{~mm}$ mark in a large percentage of years. On the one hand, this confirms the hypothesis that the main problem is not lack of water, but uneven distribution of rainfall. On the other hand, these results show that EMBRAPA can disseminate these technologies among the farmers and expect a high chance of success. However, before doing this, upmost priority should be given to a feasibility analysis of the proposed technologies at the farm level. If we consider the individual disciplines involved, the priority shifts from water managenent (which developed or adapted the technology) to farm management and economics (to see if the technology is acceptable to farmers).

\section{CONCLUSION}

The central idea of this paper was to demonstrate the use of an agroclimatic model as an illustration of the general approach taken at EMBRAPA with regard to modeling and simulation. Other mode1s (e.g., pest control or cattle management models) could have been (e.g. ,
used.

On the positive side, we can list the following aspects of modeling activities at EMBRAPA:

1. Reasonable know-how has been gained with regard to the development and maintenance of computer models. Once an initial characterization of the system to be studied has been given, a preliminary version of the mathematical model and the corresponding computer program can be ready in a few weeks. Since both the model and the computer program are subject to frequent changes, the main concern shifts from formulation to maintenance. There fore, great importance is being given to modern programming techniques (mainly top-down, modular, and structured programming) to simplify the maintenance work.

2. There is a large amount of climatic data. In fact, many stations have collected these data for more than 60 years, which places Brazil in a very good position to undertake climatological studies.

3. EMBRAPA's researchers are very interested in using computer models. The experience has made it clear that computer technology offers perhaps the only avenue for studying many complex systems.

On the negative side, we can mention two problems that will certainly receive much attention in the near future:
1. An on-line climatic data base is not available. For the most part, weather data are still in sheets and books scattered throughout the country. Thus, although many climatic models can be developed quickly, they cannot be put into operation because the data are not readily available for computer processing. In other words, modeling know-how is far ahead of the availability of the information systems needed to use the models.

2. Although EMBRAPA's computer installations in the field of scientific data processing are among the best ir Latin America, due to telecommunication problems most research stations do not have as yet remote terminals linked to the centrai computer. This is the case, for instance, of CPATSA, where computer processing is done at headquarters and outputs are mailed to the researchers. As can be expected, this creates considerable difficulties.

Once these problems are solved, the use of computer modeling and information systems in connection to agroclimatic studies will become a matter of routine. In the meantime, even with the difficulties mentioned, models are being used at EMBRAPA to set some research priorities. For instance, the model presented in this paper had a significant impact on project formulation during CPATSA's last annual programming meeting (August 1981). Several field experiments with different crops will include measurements of the parameters required by the model (e.g., root and caropy development, length of the various phases of the plant cycle, plart response to water stress, etc.), even though these measurements are not among their main objectives. Thus, several researchers clearly understand that they can use the model to save time in their future work.

\section{REFERENCES}

Ackoff, R.L. 1979a. The future of operational research is past. J. of the Operational Res. Soc. 30:93-104.

. 1979b. Resurrecting the future of operational research. J. of the Operational Res. Soc. 30:189-99.

Alves, E.R. de A. 1975. O enfoque de sistemas na EMBRAPA. Brasilia: EMBRAPA.

Birnbaum, P.H. 1979. Academic interdisciplinary research: Problems and practice. R \& D Management 10:17-22.

Dalton, G.E., ed. 1975. Study of agricultural systems. London: Applied Science Publishers.

Dent, J.B. and Anderson, J.R., eds. 1971. Systems analysis in agricultural management. New York: Wiley.

Doorenbos, J. and Kassam, A.H., eds. 1979. Yielć response to water. Irrigation and Drainage Paper No. 33. Rome: FAO.

Payne, R. and Pearson, A. 1979. Conference Report. Interdisciplinary research groups: An international comparison of their organization and management. K \& D Management 10:35-37.

Spedding, C.R.W. 1979. An introduction to agricultural systems. London: Applied Science Publishers. 